\title{
Integrating transformative learning and action learning approaches to enhance ethical leadership for supervisors in the hotel business
}

\author{
Saranya Boonyuen ${ }^{1 a}$, Suwithida Charungkaittikul ${ }^{2}$ and Archanya Ratana-ubol ${ }^{2}$ \\ ${ }^{1} 100 / 416$ Moobannakeela Soi 28, Sapansoong, Bangkok 10250, Thailand \\ ${ }^{2}$ Life Long Learning Department, Faculty of Education, Chulalongkorn University, Phayathai Road, \\ Bangkok 10330, Thailand
}

\begin{abstract}
Ethical leadership is now increasingly focused in leadership development. The main purpose of this study is to explore two methods of adult learning, action learning and transformative learning, and to use the methods to enhance ethical leadership. Building ethical leadership requires an approach that focuses on personal values, beliefs, or frames of references, which is transformative learning. Transformative learning requires a series of meetings to conduct critical discourse and to follow up the learning of learners. By organizing such action learning, human resource developers can optimize their time and effort more effectively. The authors have created a comprehensive model to integrate the two learning approaches in a general way that focuses not only on ethical leadership, but also on all kinds of behavioral transformation in the workplace in the hotel business or even other types of business.
\end{abstract}

\section{Introduction}

In a workplace like hotels, leaders have crucial roles to educate teams about ethical matters both in general actions and interactions with others. We cannot expect people to pursue ethical behaviors without any critical discourse on why their original assumption is no longer acceptable. We need a transformative learning process which allows learners to become critically aware of how their psycho-cultural assumptions have resulted in constraints, and then with critical discourse, learners can reevaluate their own assumptions to be more inclusive and discriminating, open, reflective and eventually be able to change their habits of mind and eventually transform both their minds and behaviors.

According to Jack Mezirow's Transformative Learning theory, people construct frames of reference unconsciously in each life event based on various sources, such as family upbringing, school, general direct experiences, and indirect experiences including occasional life crises. These frames of reference are bases which people use to judge and

\footnotetext{
${ }^{a}$ Corresponding author: saranmuk@gmail.com
} 
give meaning to their world. These frames of reference also help to form their expectations and assumptions and encourage consistent interpretations. This consistent description of interpretation is called the "habits of mind". These habits of mind then become the main reasons why people react to the situations faced in daily life.

Transformative learning basically requires a series of meetings to conduct critical discourse and to follow up on the progress of learners. However, taking staff away from their duty for long or frequent periods of time is a real challenge for the hotel business, and in a workplace like hotels, human resource developers cannot afford to spend their time and effort to conduct individual critical discourses with each supervisor. They need a practical approach to organize the coaching sessions more effectively. The study will explore ways to integrate transformative learning and action learning approaches to enhance ethical leadership for supervisors in the hotel business.

\section{Theoretical Framework}

Brown et al [1] defined ethical leadership as the demonstration of normatively appropriate conduct through personal actions and interpersonal relationships, and the promotion of such conduct to followers through two-way communication and decision making. Ethical leadership has been discussed recently by numerous scholars in the field of organizational behavior and management with respect to its impact on individual, group, and organizational outcomes.

Leading ethically is believed to be a process of inquiry, asking questions about what is right and what is wrong- and a mode of conduct- setting an example for followers and others about the rightness and wrongness of particular actions [2]

Transformative learning may be defined as learning that transforms problematic frames of reference to make employees more inclusive, discriminating, reflective, open, and emotionally able to change [4]

The transformative learning process in general will be in a dialogue or discourse called 'critical dialogue' or 'reflective dialogue'. Mezirow and Associates [5] stated that the process in dialogue will be for disorienting dilemma, self-examination, self-questioning, self-awareness, exploration of options for new roles, planning of a course of action, understanding of how to act, trying of new roles, positive feedback and reintegration.

Ideal conditions for reflective dialogue include the provision of the most accurate and complete information, ensuring freedom from coercion and distorting self-deception; encouraging an openness to alternative points of view, thus ensuring equal opportunity to participate in various roles of discourse; and by "encouraging a willingness to seek understanding and agreement to accept a resulting best judgement as a test of validity until new perspectives, evidence, or arguments are encountered and validated through discourse as yielding a better judgment" [5].

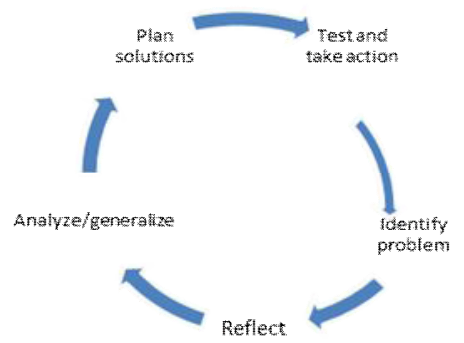

Figure 1: Action Learning Cycle of Learning [3] 
Action learning is both a process and a powerful program that involves a small group of people solving real problems while at the same time, focusing on what they are learning and how their learning can benefit each group member and the organization as a whole [3].

Action Learning [3] is built upon the entire learning cycle: learning and creating knowledge through concrete experience, observing and identify the problem, reflecting on this experience, experimenting, analyzing and forming generalizations from experiments, planning solutions, testing the implications in new experiences, and beginning the process again (see Figure 1).

An action learning program is organized by providing related formal knowledge by a facilitator. The group will then be divided into sets of 4-8 persons if the first session is a bigger group. Each set, which is led by a facilitator, meets regularly to share and identify problems, to reflect and to form new learning including setting up action plans for specific solutions. The program may last from 1 month up to one and a half years.

\section{Research Methodology}

This study employed qualitative approaches by employing the ten steps of the perspective transformation process proposed by Mezirow [4 and 5] and the action learning group process and organization of Marquardt [3]. The research methodology also consisted of documentary review of theories, principles, and other related research papers. The data were analyzed and synthesized to develop a draft integrated learning model to develop a workplace learning program to enhance ethical leadership for supervisors in the hotel business.

\section{Results and Discussion}

Resulting from the documentary review and interviews with experts, the authors have developed a comprehensive model that is the integration of ways to organize programs of action learning and the transformative learning process as shown in Figure 2.

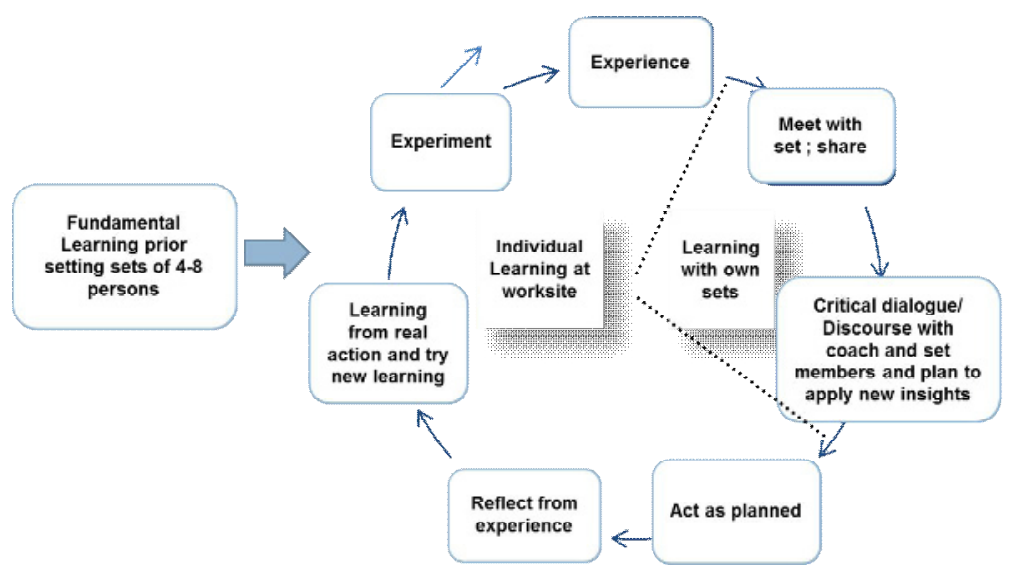

Figure 2: Integrated Model of Action Learning and Transformative Learning Methods 
The model shows how to organize a program in the workplace, in this case, a hotel business. From the model, there are three types of learning - fundamental learning, learning in their own sets and individual learning at the worksite.

Fundamental Learning: The number of participants can vary in accordance with the program methodology. The program starts with providing learners fundamental learning, which in this research will be related to ethical leadership. The content will be background information on the aim of the program, in this case "ethical leadership", and the how- to of being ethical leaders. After that, participants will be informed about the learning process of action learning and the participants' role and responsibility as learners and set members. At the end of the session, the participants will be divided into sets of 4-8 persons, preferably from different backgrounds. Ideally to create sprit of teamwork, the sets are asked to create a set name and the set's ground rules of learning.

Learning in Their Own Sets: Prior to starting the program, the set members and 2 followers are asked to complete the Ethical Leadership Scale [1] to assess the level of ethical leadership of all participants. The second meeting will involve learning in their own sets, which starts with a small group session. The facilitator shows each member the results of the assessment and explains the way to analyze the results. Each participant will identify at least 3 key priorities upon which they will then focus. The facilitator gives each participant time to reflect and think, starting with the reasons to choose the priorities, and at that point, the facilitator leads the critical dialogue adding the knowledge and experience of other set members. The session may include storytelling or other tools that help set members follow the process of transformative learning. Each set member will leave each session with an action plan to apply new insights from the meeting in their workplace with their own followers and in their context for at least one week.

Individual Learning: Each learner starts to act as planned and records the experience in a personal learning journal which will be shared on-line in "Google docs" with other set members and the facilitator subject to his/her permission. To complete the journal, each learner will reflect the experience of plan implementation, and record the learning from their own experience in the workplace. Each learner may try and record other ways if the plan does not work as well as expected. This experiment will eventually become a new frame of reference for the learners to employ when facing similar experiences in the future. This is how transformative learning occurs individually.

Once they meet the sets in the meeting; each set member is asked to share any success and new learning with other set members and from here, the critical dialogue starts again. The plan for action can be for a previously unsuccessful action, with regard to a priority which had been determined in an earlier individual learning session. If individual learning is productive, the focus can move in other directions.

The group will continue to meet until the end of the program. Where the period is long, the forum can be organized as a knowledge sharing exercise by bringing in learners from other sets to share their experience and learning.

The authors found the integration of two learning methods is very practical especially in a workplace like a hotel. The practical logistics of an action learning help the facilitator to have clear guidelines to organize the group, create the sets and the ways to facilitate the sets. However, to conduct critical dialogue; a facilitator needs to ensure the environment is relaxed and comfortable, which encourages participants to be willing to disclose self and to be open to new ways of looking at each frame of reference. The team members of the sets can then provide beneficial information and share related experiences.

It is advised that conducting transformative learning as a group requires a qualified facilitator. This is to ensure the atmosphere is productive and with freedom from coercion and self-deception so all the members are willing to participate in the session and to build meaningful relationships with other members of the sets naturally. 


\section{Summary}

Developing ethical leadership will be increasingly the focus of organizations; however, it is also challenging to make people change the way they think without any well planned process of transformation. The model developed by the authors can be used as an initial guideline about how to organize a program. The authors are now in the process of developing details about how to conduct the whole program with a reliable instrument to evaluate the development of the learners. Although the development of the research is based on the hotel business context, the authors believe the model can be applied in other contexts, regardless of the workplace or community. The authors also believe that the model can be used as a transformation tool for any kind of habit of mind, regardless of the social or professional context.

Remarks This paper is part of a full research on "The Development of a Workplace Learning Program by Integrating Action Learning and Transformative Learning Theories to Enhance Ethical Leadership for Supervisors in the Hotel Business"

\section{References}

1. Brown, M. E., Trevino, L. K., Harrison, D. A., Ethical Leadership: A social learning perspective for construct development and testing. Organizational Behavior and Human Decision Process, 97 (11), 117-134 (2005)

2. Guy, M.E., Ethical Decision making in everyday work situations: Greenwood Publishing Group (1990)

3. Marquardt, M. J., Action Learning in Action (1st ed.). USA: Davies-Black (1999)

4. Mezirow, J., Transformative Learning Theory. In J. Meziro, E. W. Taylor \& Associates (Eds.), Transformative Learning in Practice (pp. 18-31). USA: Jossey-Bass (2009)

5. Mezirow, J., \& Associates., Learning as Transformation. San Fransisco: Jossey-Bass (2000) 